\title{
Reducing Households' Energy Use: A Segmentation of Flanders on Adoption Intention of Smart Metering Technology
}

\author{
Jeroen Stragier $^{1, *}$, Laurence Hauttekeete ${ }^{1}$, Lieven De Marez ${ }^{1}$ \\ ${ }^{1}$ IBBT-MICT-Ghent University, Ghent, Belgium \\ *Corresponding author. Tel: +3292649745, Fax: + 3292646992, E-mail: Jeroen.Stragier@Ugent.be
}

\begin{abstract}
Research has shown that feedback on energy use can aid households to reduce it significantly. In this context, smart metering technologies, and more specifically technology components interacting with data gathered and provided by a smart meter, allowing to provide the consumer with personalized feedback, consumption visualization, automated control,... could play an important role. After all, by means of this technology, households can be made more aware of their energy use and encouraged to reduce it. This paper applies a user centered approach towards the estimation of the adoption potential for smart metering technologies in Flanders, Belgium. We conducted a representative quantitative survey with 1314 respondents living in Flanders. A segmentation on ownership of, attitude towards and adoption intention of smart metering devices was performed on the data. Traditional approaches of intention surveying often result in an overestimation of the innovation adoption potential. To overcome this problem, the Product Specific Adoption Potential scale (or PSAP-scale) was used and 6 segments were found. These segments were labeled "Current Owners", "Innovators", "Early Adopters”, "Early Majority”, "Later Adopters” and "Out of Potentials. The verification of the adoption potential of smart metering devices for different pricing scenarios revealed a rather high price sensitivity.
\end{abstract}

Keywords: Consumer behaviour, smart metering, adoption potential, willingness to pay

\section{Introduction}

Most residential energy users are not aware of their usage pattern. On a global level, the amount paid every month is the only indicator of energy use for the majority of the households. On appliance level, households have little or no knowledge on the amount of energy that their appliances consume, or its share in the total household energy use. Mansouri-Azar et al. [1] proved that a majority of their respondents did not know which of their electric appliances consumed most energy. At the time the research was carried out, lighting, freezer and dishwasher were the most consuming appliances in the UK households. Nonetheless, most of the respondents mentioned the washing machine in their top three.

The positive effect of feedback on energy use has been examined and confirmed in many studies [2-6]. It is generally recognized that households can be motivated to reduce their energy use when receiving correct feedback. Several forms of feedback can be distinguished ranging from more detailed billing over comparative and historic feedback to direct feedback at the time of use. According to Raaij and Verhallen [7] feedback has three functions:

(1) learning: the provided feedback gives the consumer information on the results of certain actions;

(2) habit formation: the feedback helps in forming certain new habits with regard to energy conservation. These habits should remain when the feedback is removed;

(3) internalization of behaviour: feedback helps to create new attitudes and habits that become embedded in a person's behaviour. These habits and attitudes will influence energy-related actions in situations where the feedback will not be present.

Smart meters can play an important role in providing this feedback to consumers and many applications are possible. Smart meters connected to in-home displays, internet applications, 
smart phone and tablet apps can provide residential consumers with basic insight into their energy use at a given time during the day, but the possibilities go far beyond this. Smart appliances connected to smart meters can stimulate an efficient appliance use supported by time-of-use pricing mechanisms and availability of renewable energy sources. The question however remains to what extent the consumer is interested in adopting these smart metering applications and, from a business perspective, what is their willingness to pay for these applications? These two questions will be addressed in this paper.

\section{Methodology}

We conducted a quantitative survey with a representative sample of the population of Flanders, Belgium. The questionnaire was designed to make a segmentation based on attitude towards smart metering technologies and distributed through both online and offline channels in June, 2010. A total number of 1314 respondents completed the survey.

Two parameters were taken into account for creating the segmentation: the ownership of smart metering devices (such as power meters) and the interest and purchase intention of smart metering devices.

The first parameter could easily be measured using one question asking for the ownership of these smart metering devices.

The second parameter concerns the interest and purchase intention of devices for smart metering in terms of adopter segments as formulated in diffusion theory [8]. According to this diffusion theory, the adoption of an innovation depends largely on a person's innovativeness determined by the moment upon which a person decides to start using an innovation. The diffusion of an innovation in a social system follows a clockwise pattern. Rogers [8] distinguishes between five adopter segments. The Innovators (2.5\% of the population) are the most innovative group of adopters. They will be among the first to adopt an innovation, followed by those categorised as Early Adopters (13.5\%), Early Majority (34\%), Late Majority (34\%) and Laggards (16\%). In order to assign the respondents to one of the adopter segments for smart metering devices, the Product Specific Adoption Potential scale (PSAP) [9-11] was used. The scale was developed as a valid alternative to traditional single-intent questions used in traditional market research, which systematically lead to over- or underestimation of the adoption potential of innovations. The model has been validated for several innovations (e.g. [11, 12]). Instead of a single intent question asking for the adoption likelihood of an innovation, three questions are asked. The adoption intention is measured for optimal and suboptimal product offerings. A calibration heuristic based on the answers on all 3 intention questions assigns the respondent to the appropriate adoption segment [9].

First, the respondents received an introductory text about smart metering devices and their possibilities. Smart metering was described as the use of a new type of electricity meter, which offers households the ability of closely monitoring their energy consumption. After reading this text, the first (traditional) intention question was asked (PSAP question 1): "If you would have the opportunity tomorrow to buy a smart metering device, to what extent do you think that you would buy this device"? The answering scale provided 5 possible answers:

- I would immediately buy this device;

- There is a large probability that I would buy this device;

- I think I would wait, maybe later;

- I don't think I would buy this device; 
- I definitely won’t buy this device.

Second, the respondents were asked to rate 10 possible use cases of smart metering on a 5point scale ranging from "not interested at all" to "very interested". The use cases were:

- Receiving personalized tips to save energy based on your energy usage data;

- Insight in your energy use in real time at every moment of the day;

- Receiving graphs and reports with an overview of the total energy use in a certain period;

- Postulate goals to save energy in the future;

- Making an estimation of the future energy use during a certain period;

- Comparing your energy use with other (comparable) households or houses (e.g. in your neighbourhood);

- Receiving feedback when the energy use exceeds that of a previous comparable period;

- Entering in competition with other households to keep the energy use low;

- Graphs and reports with detailed energy use data per appliance;

- Automatic switch-on/-off of appliances, based on time of the day (e.g. day/night).

Furthermore, the respondents were asked to specify an "acceptable price limit" they are willing to pay for a smart metering device that is capable of providing the 10 use cases that we provided in the previous question. No limitations were imposed. The respondents were free to give any price they thought was acceptable.

After these questions, a second more personalized intention question was asked (PSAP question 2). This time, an ideal product was composed using those use cases from the aforementioned list of 10 that the respondent was either "interested" or "very interested" in. This ideal product was then presented as a "smart metering offer" at a price that was acceptable for the respondent, according to the price limit (s)he had indicated, and containing all the applications/use cases (s)he was interested in. Hence, every respondent had to give their adoption intention for this ideal product at their ideal price (which was different for every respondent).

Finally, a third intention question was asked (PSAP question 3). This time, the adoption intention for a "suboptimal product" was measured. Again their ideal product was provided, but at a higher price than the limit they indicated (the ideal price was raised with $20 \%$ ).

Based on a calibration heuristic, checking for the consistency in intention statements over the different answers on the 3 PSAP questions, each of the respondents was assigned to one of the adopter segments: Innovators, Early Adopters, Early Majority, Late Majority and Laggards.

Furthermore, 2 more segments were added to the segmentation: "Current Owners" and "Out of Potentials". Current Owners are those who indicated that they already possess certain smart metering devices. Although they don't possess a smart meter yet, they have already invested in devices with similar possibilities. Out of Potentials are respondents that showed no interest in any of the use cases that were provided. Late Majority and Laggards were merged into one single segment labeled "Later Adopters" due to small socio-demographic and attitudinal differences. 


\section{Results}

\subsection{Segmentation on attitude towards smart metering}

Figure 1 indicates that a market potential exists for smart metering in Flanders, as the high proportion of Current Owners, Innovators and Early Adopters and Early Majority indicates. Still, there is also a high proportion of Out of Potentials, which indicates that for certain consumers, using smart metering is already out of the question, no matter the cost of the investment.

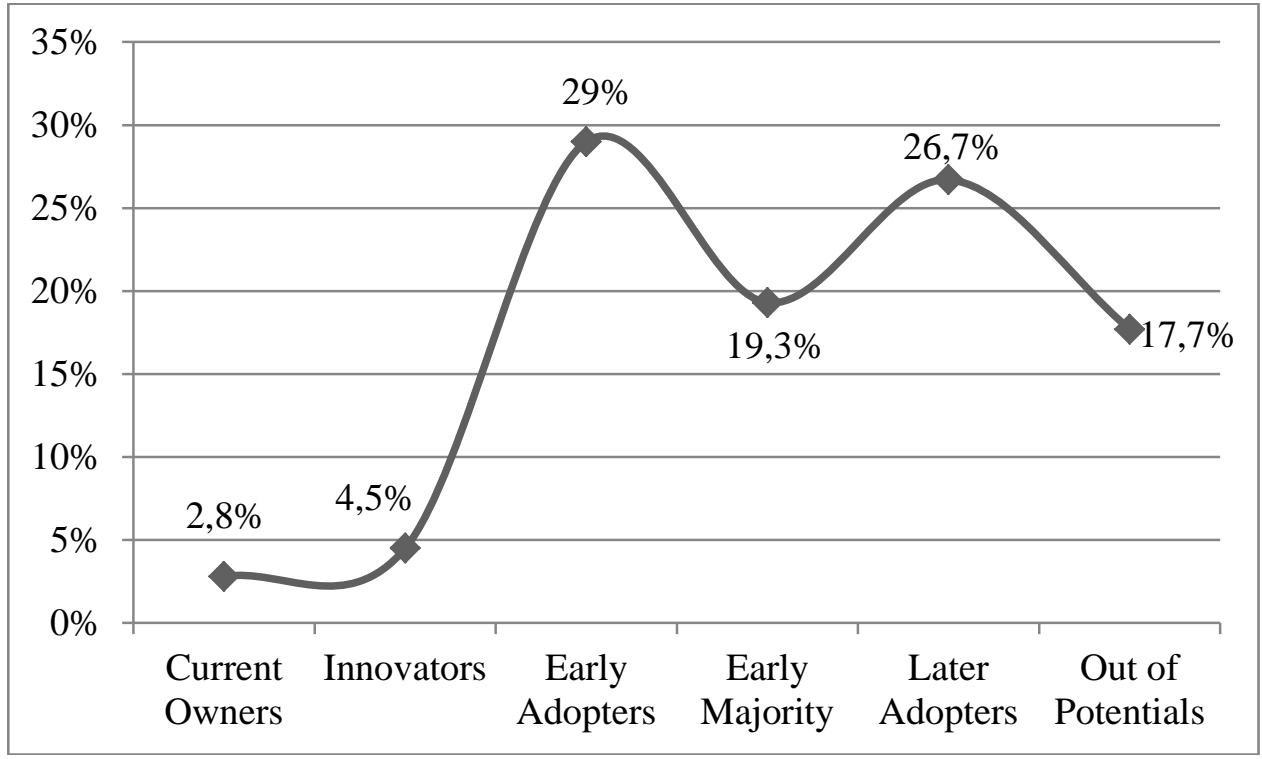

Fig. 1. Segmentation of Flanders on attitude towards smart metering.

Current Owners are the segment that already made some (minor) investments in equipment with smart metering capabilities. These Current Owners were identified by asking for the ownership of appliances that have smart metering capabilities (after being given an introductory text to the possibilities of smart metering). 40 respondents indicated to have such an appliance. When asked for the capabilities of their appliance, ... $75 \%$ of them appear to have one that displays the energy use per appliance, $20 \%$ has a device that displays the total energy use and $5 \%$ has a tool that allows monitoring the energy use per circuit. The Current Owners are among the "younger" respondents (average age $=44.3$ years). They mainly live in younger households with children.

Innovators are the first segment that did not yet invest in appliances for energy use monitoring. They are very interested in using smart metering devices and exploiting the possibilities. The average age within this segment is 44.8 which makes them on average as old as the Current Owners. The majority of them is married and/or has children. Early Adopters are also interested in using smart metering devices, but to a lesser extent than the Innovators. They are somewhat more reserved. The average age within this segment is 46.3 years. The Early Majority can still be situated within the same age category as the Early Adopters and Innovators (average age: 46.5 years), but they are the less interested group. Their interest in and buying intention of smart metering devices is again lower than that of the previous segments. The difference between the Later Adopters and the previously mentioned segments is larger. Their interest and buying intention of smart metering devices is quite low. The average age in this segment is 50.5 which makes it significantly older than the other segments. Out of potentials are completely uninterested in smart metering devices. They are the oldest 
segment (with an average age within the segment of 54.6 years). More than a third of them are retired.

\subsection{Willigness to pay}

Of course, an important factor is the willingness to pay for a smart metering device. The adoption potential forecast for smart metering devices presented in figure 1 is not only based on interest, but also on an assessment of their willingness to pay. However, it is important to keep in mind that this first forecast is based on a scenario without pricing restrictions. The respondents had to indicate which price they are willing to pay for a smart metering device, without any control mechanisms or checks whether the indicated price is also a feasible price for the supply side. Therefore, a next step must be a comparison of the adoption potential for different pricing levels.

The PSAP-scale allows checking the possible influence of pricing. Five scenarios were created in which a cut-off ( $€ 50, € 100, € 150, € 200, € 300)$ was made at a given price. Figure 2 presents these five scenarios.

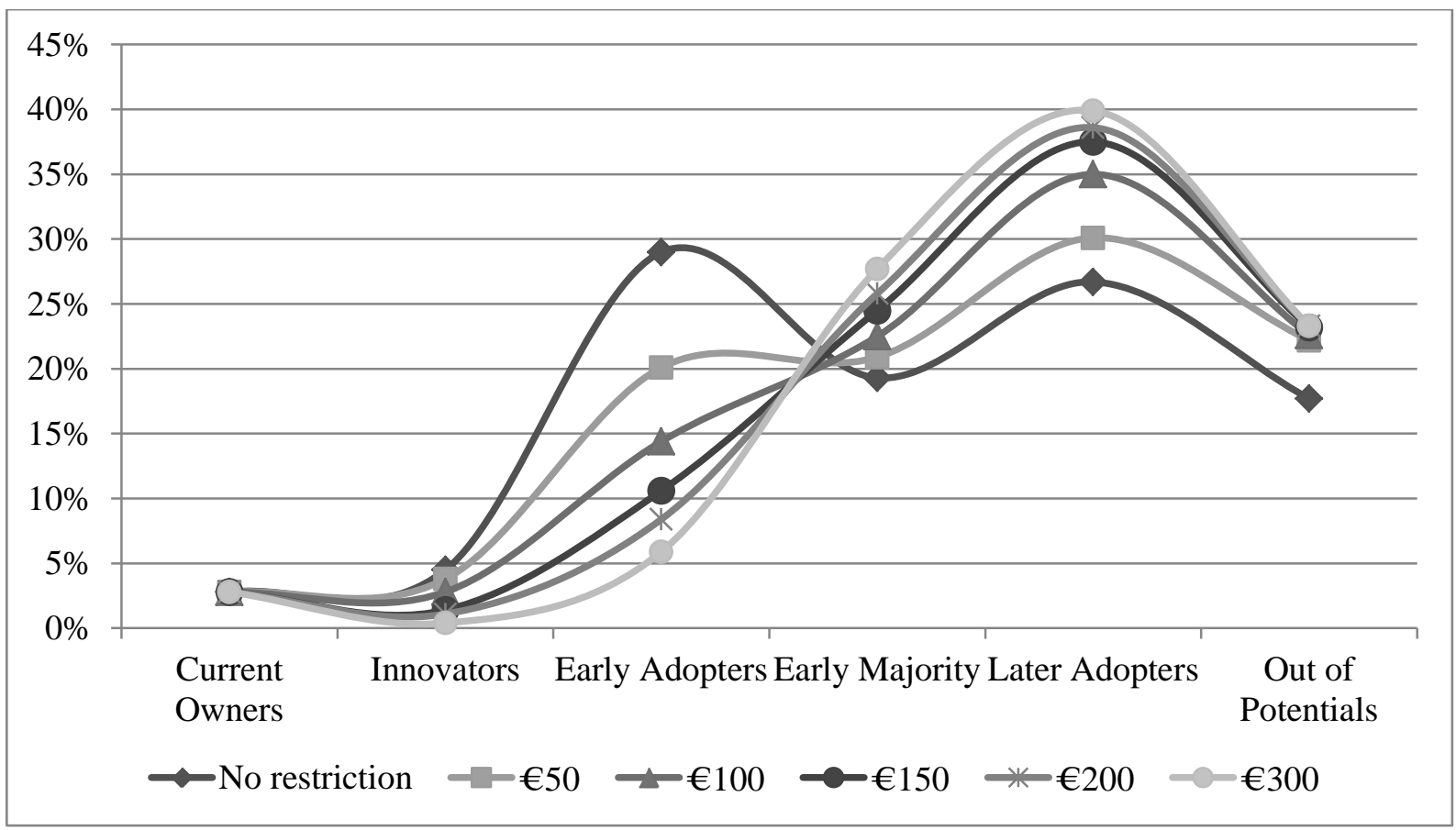

Fig. 2. Adoption potential curves for different pricing scenario.

Evidently, it can be assumed that enthusiasm will decrease as the pricing of the smart metering device increases. The question however is how much potential will be lost with each price increase? In the context of delineation of target markets and business cases it will be important to determine a kind of "tipping point" where a certain price increase holds the risk for a too big loss of potential. The "No restriction" scenario provides the original segmentation, in which the respondents could freely indicate how much they are willing to pay for their "ideal" smart metering device. Each of the succeeding scenarios ( $€ 50, € 100$, $€ 150$, €200, €300) gives the cut-off that was set. If the price that a respondent was willing to pay is lower than the cut-off that was set, the respondent shifts back one segment in the segmentation. In other words, respondents that combine a high enthusiasm for smart metering with a less realistic willingness to pay (according to the cut-off), slide to the rear of the segmentation. In the scenario in which the smart meter is offered at $€ 100$ for example, an 
initial innovator will not remain an innovator if (s)he indicated his/her willingness to pay to be e.g. $€ 60$ or $€ 80$.

As can be seen in figure 2, it is clear that the enthusiasm for smart metering is accompanied by a rather high price sensitivity. Where the forecasted size of the innovator segment in Flanders (originally $4.5 \%$ ) remains almost $4 \%$ and $3 \%$ in the $€ 50$ and $€ 100$ scenario, it shrinks to $1 \%$ or less if the price threshold of $€ 150$ is surpassed. The Early Adopters segment shows a significant drop in size (from $29 \%$ to $20 \%$ ) when a pricing restriction of $€ 50$ is imposed. In spite of their high interest in smart metering devices, a considerable proportion of Early Adopters shows a rather low willingness to pay. The drop in size of the segment continues over the following pricing scenarios with a tipping point around $€ 100-€ 150$. After this point, the divergence in the curves remains rather low.

\section{Discussion}

Providing insights and feedback about energy use is an essential means to create awareness and encourage an efficient energy conservation behaviour. Smart metering can be an excellent means to provide this feedback in real time. However, the question is who's interested in adopting this technology and what is their willingness to pay? In this paper, a segmentation on the adoption potential of smart metering devices was presented. Only a small proportion already own devices with some smart metering capabilities. This segment was called "Current Owners". The rest of the sample was classified in adopter segments. The large proportion of Early Adopters indicates a substantial base of interest in the possibilities of smart metering with regard to energy conservation for households. However, when different pricing scenarios for a smart metering device were applied to the data, a significant drop in the Innovator and Early adopter segments was noticed. In this research, the respondents were asked to indicate the price they are willing to pay for a smart metering device, without any checks whether their indicated price is also a realistic one. The results indicate that households want to invest in energy efficiency, as could be seen from the interest in smart metering devices, but the return must be worth the investment. Therefore, the yearly household electricity use is important to keep in mind. The average consumption of a household in Flanders is about 3500-4000 kWh per year, which corresponds with about €550-€650 per year. If e.g. a saving of $10 \%$ can be realized using smart metering devices, this leads to reduction of around $€ 60$ on the yearly electricity bill. For households with a significantly higher electricity use, high investments will be more relevant and therefore, their willingness to pay will be higher than that of households with an average electricity use.

\section{Acknowledgement}

This article is based on results from the SmartE project which is funded by IWT and various partners: IBBT, IBBT-iLab.o UGent-MICT, UGent-IBCN, KULeuven-CUO, KULeuvenESAT-Electa, VITO, VUB-SMIT, Telenet, SPE-Luminus, Alcatel-Lucent Bell, Niko, Ferranti and Xemex.

\section{References}

[1] I. Mansouri-Azar, M. Newborough, and D. Probert, "Energy-consumption in UK domestic households: impact of domestic electrical appliances," Applied Energy, vol. 54, pp. 211-285, 1996.

[2] C. Fischer, "Feedback on household electricity consumption: a tool for saving energy?," Energy Efficiency, vol. 1, pp. 79-104, 2008. 
[3] A. Faruqui, S. Sergici, and A. Sharif, "The impact of informational feedback on energy consumption--A survey of the experimental evidence," Energy, 2009.

[4] R. M. J. Benders, R. Kok, H. C. Moll, G. Wiersma, and K. J. Noorman, "New approaches for household energy conservation--In search of personal household energy budgets and energy reduction options," Energy Policy, vol. 34, pp. 3612-3622, 2006.

[5] L. T. McCalley and C. J. H. Midden, "Energy conservation through product-integrated feedback: The roles of goal-setting and social orientation," Journal of Economic Psychology, vol. 23, pp. 589-603, 2002.

[6] S. Darby, "Making it obvious: designing feedback into energy consumption," 2001.

[7] W. F. Van Raaij and T. M. M. Verhallen, "A behavioral model of residential energy use," Journal of Economic Psychology, vol. 3, pp. 39-63, 1983.

[8] E. M. Rogers, Diffusion of innovations, 4th ed. New York (N.Y.): Free press, 1995.

[9] L. De Marez, "Diffusie van ICT-Innovaties: Accurater Gebruikersinzicht Voor Betere Introductiestrategieën," Gent: Universiteit Gent, 2006.

[10]L. De Marez and G. Verleye, "ICT-innovations today: making traditional diffusion patterns obsolete, and preliminary insight of increased importance," Telematics and Informatics, vol. 21, pp. 235-260, 2004.

[11]L. De Marez, P. Vyncke, K. Berte, D. Schuurman, and K. De Moor, "Adopter segments, adoption determinants and mobile marketing," Journal of Targeting, Measurement and Analysis for Marketing, vol. 16, pp. 78-95, 2007.

[12]T. Evens, D. Schuurman, L. De Marez, and G. Verleye, "Forecasting broadband Internet adoption on trains in Belgium," Telematics and Informatics, vol. 27, pp. 10-20, 2010. 